\title{
THE CENTRE OF CRAFT POTTERY NEAR SUVOROVSKAYA COSSACK VILLAGE AMONG THE SETTLEMENT SITES OF SALTOVO-MAYAKI CULTURE IN THE LOWER DON REGION
}

\author{
Yakov A. Kiyashko \\ Volgograd State University, Volgograd, Russian Federation
}

\begin{abstract}
This article is devoted to the review of the results which were received during the archaeological excavations on the site of Saltovo-Mayaki culture near Suvorovskaya Cossack village in the Volgograd region. The first archaeological research was carried out in the investigated area in 1951. Later, it was supposed that the site had been wiped out during the construction of Tsimlyanskoe water reservoir. But the results of archaeological excavations in 2011-2012 refuted this data and allowed to discover the objects of ceramics such as kilns and the remnants of ceramic production.

This work gives the description of two pottery kilns which were found during the archaeological excavations in 2012 and a short analysis of ceramics. A lot of typical fragments of dishes were discovered at the site such as tablespoon glazed jars, pots with a specific linear ornament and cauldrons with inside handles. It is worth mentioning that the biggest part of dishes had defects and these defective utensils were kept in the certain places. The molted ceramics and amphoras which are often presented at the sites of Saltovo-Mayaki culture were not found.

Thereby, during the study of the Suvorovskaya I site the author found a few pottery kilns, the places of ceramics garbage and the household objects which should be workshops of the craftsman. According to the study, the Suvorovskaya I site is a specialized pottery center. If the hypothesis is correct, it will be possible to speak about the allocation of a separate type of archaeological site which can be marked by a highly specialized activity for production of high-quality pottery products. And it also gives the opportunity to talk about craftsman as the specific group of population who did not take part in farming.

The following excavations are very important for the reconstruction of social, economical and ethnocultural processes in Khazar Khanate.
\end{abstract}

Key words: earlyMiddle Ages, Khazar Khanate, Saltovo-Mayaki culture, the Lower Don, craft pottery production.

\section{ГОНЧАРНО-РЕМЕСЛЕННЫЙ ЦЕНТР У СТАНИЦЫ СУВОРОВСКОЙ В СТРУКТУРЕ ПОСЕЛЕНЧЕСКИХ ПАМЯТНИКОВ САЛТОВО-МАЯЦКОЙ КУЛЬТУРЫ НА НИЖНЕМ ДОНУ}

\author{
Яков Алексеевич Кияшко \\ Волгоградский государственный университет, г. Волгоград, Российская Федерация
}


Изучение памятников салтово-маяцкой культуры степи Нижнего Дона представляет значительный интерес. Концентрация археологических объектов VIII-IX вв. здесь достаточно велика, что позволяет говорить о значимости этого региона в то время. Это стало известно благодаря археологическим работам, которые проходили на территории строительства будущего Цимлянского водохранилища в конце 40-х - начале 50-х гг. XX века. В указанное время было принято решение об организации Волго-Донской археологической экспедиции для изучения археологических памятников, попадающих в зону затопления.

В составе данной экспедиции два года работал разведывательный отряд во главе с И.И. Ляпушкиным. Перед отрядом была поставлена задача произвести сплошное обследование зоны затопления с целью выяснения археологического облика района. Вместе с тем на отряд было возложено производство археологических раскопок разведочного порядка на наиболее важных обнаруженных памятниках [4, с. 227].

Территория исследований захватила оба берега реки Дон, от Калачевского района Волгоградской области (хут. Малая Набатовская) до ст. Цимлянской Ростовской области (предположительно место будущего затопления). Работа отряда длилась два летних сезона 1950-1951 годов. Было обследовано более 60 памятников, в основном поселений, которые относятся к разным археологическим эпохам. Среди них стоит выделить группу поселений салтово-маяцкой археологической культуры, которые находились как по берегу реки Дон, так и по берегу реки Чир и у озера Ильмень $[4$, c. 255-260]. Особый интерес представляет открытие салтово-маяцкого поселения недалеко от станицы Суворовской Суровикинского района Волгоградской области (см. рис. 1). Открытые на памятнике гончарно-ремесленных объектов позволило исследователю предложить типологию керамического материла, а также выделить некоторые особенности нижнедонского варианта салтово-маяцкой культуры [5, с. 107-116].

В 2011-2012 гг. автором статьи были продолжены археологические исследования на поселении у станицы Суворовской. Целью предлагаемой статьи является введение в научный оборот новых данных, полученных в ходе последних работ на памятнике.

Для того чтобы избежать дальнейшей путаницы, стоит сказать, что ранее памятник не стоял на государственном учете. Поэтому в ходе подготовки отчетной документации данный объект археологического наследия получил название Суворовская I.

Из описания И.И. Ляпушкина следует, что поселение примыкает к юго-восточной окраине Суворовской станицы. Оно расположено по склону высокого коренного берега, переходящего в этой части в амфитеатрообразную надпойменную террасу. Культурные остатки прослеживаются на поверхности террасы и в обрезах многочисленных разветвлений оврагов и балок, прорезающих берег в направлении от плато к долине реки. Также фрагменты керамики часто встречались в долине реки, на расстоянии до 200-300 м от коренного берега. Не исключено, что культурные остатки вынесены сюда потоками дождевых и весенних вод. Протяженность памятника по линии северо-восток - юго-запад (вдоль берега) около 700 м, по линии северо-запад - юго-восток (склон берега) около 300 м. Выходы культурных отложений наиболее отчетливо заметны в береговых отложениях оврагов. В отдельных местах мощность культурного слоя достигает 0,7 м. На большой площади памятника культурный слой сверху покрыт дерном и залегающими под ним наносами, мощность которых в некоторых точках достигает 0,4-0,5 м. Ниже культурных отложений лежит глинисто-песчанистый материк. В береговых обрезах во многих местах отчетливо прослеживаются углубленные в материк части построек, заполненные гумусированным или золистым культурным слоем с включением большого количества обломков керамики, костей животных. Значительное место в культурных отложениях занимает глиняная обожженная обмазка, выходящая на поверхность в ряде мест в виде больших линз [6, с. 321].

Впоследствии И.И. Ляпушкиным были проведены раскопочные работы на памятнике, которые были реализованы в два приема (6-10 июля 1951 г. и 25 сентября - 2 октября 1951 г.). В обоих случаях раскопки носили разведывательный характер и были посвящены исследованию тех участков, где в обрезах 


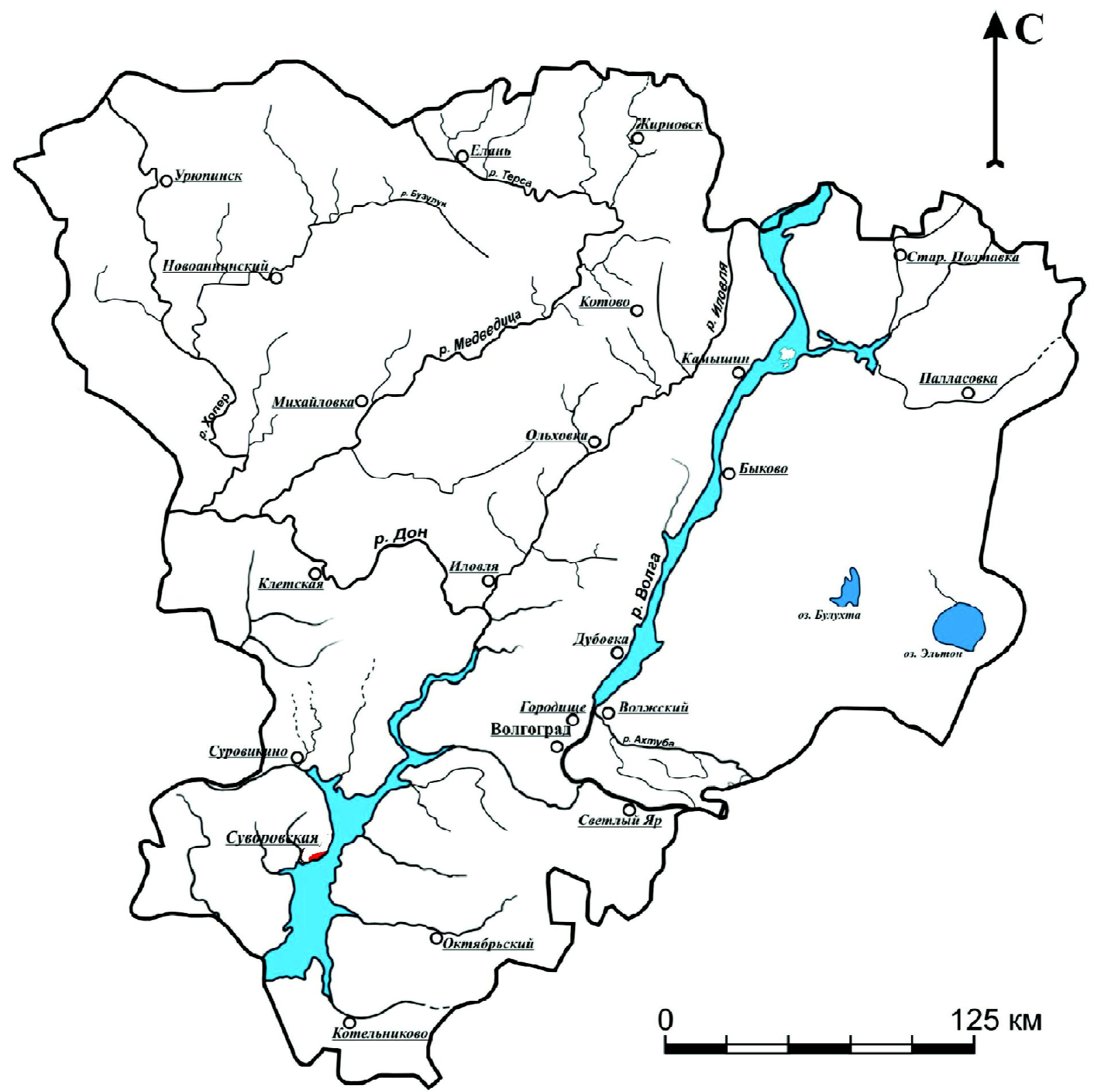

Рис. 1. План-схема расположения поселения Суворовское І у станицы Суворовской Волгоградской области

берегов оврагов и балок были отчетливо заметны ямы, врезанные в материк, а также выходы сильно обожженной глины. В процессе раскопов были обследованы гончарно-ремесленные комплексы, которые были представлены гончарными горнами, а также хозяйственными объектами (2 полуземлянки, хозяйственная яма грушевидной формы, 3 гончарные обжигательные печи) [6, с. 323-336]. Найденная в большом количестве керамика позволила отнести памятник к салтово-маяцкой культуре, а анализ материала дал возможность И.И. Ляпушкину датировать памятник VIII-X вв. [6, с. 336].
После сооружения Цимлянского водохранилища данный памятник считался утерянным для науки и его исследование практически не проводилось. Несмотря на это, прогнозы исследователей касательно масштабов зоны заполнения водохранилища себя не оправдали и оказались менее значительными, чем ожидалось.

В ходе археологической разведки по берегу Цимлянского водохранилища в 2011 г. была повторно обследована территория у станицы Суворовской. В результате осмотра стало ясно, что место, где работала экспедиция И.И. Ляпушкина, было уничтожено при созда- 
нии водохранилища. Несмотря на это, в обрезе современного берега был прослежен культурный слой, а также выходы обожженной обмазки. Собранный подъемный материал и наличие гончарно-обжигательных горнов, следы которых были найдены при зачистке береговых обнажений, позволили отнести археологический объект к салтово-маяцкой культуре. Таким образом, осмотр памятника показал, что открытое в начале 50-х гг. ХХ в. в ходе работы Волго-Донской археологической экспедиции Суворовское поселение не было уничтожено при сооружении Цимлянского водохранилища. При этом в течение последующего времени оно подвергалось ежегодному разрушению по причине разлива вод водохранилища в период весенних паводков. Определенный ущерб поселению был также нанесен при осуществлении хозяйственной деятельности местными жителями. Исходя из этого, было принято решение провести археологические раскопки тех участков памятника, которые находятся под непосредственной угрозой обрушения.

Для проведения археологических работ был снят подробный топографический план, из которого следует, что памятник Суворовское I расположен на второй надпойменной террасе реки правого берега Дона, которая в настоящее время была частично размыта водами Цимлянского водохранилища (рис. 2). Данный археологический объект занимал участок террасы, изрезанный многочисленными оврагами, верховья которых сохранились до настоящего времени. Территория сохранившейся части поселения вытянута по краю береговой линии с запада на восток примерно на 200 м, ширина (по линии север - юг) составляет около 140 м. С севера и запада памятник граничит с современной станицей Суворовской. Южную границу памятника проследить невозможно, так как на сегодняшний день она уничтожена сооружением водохранилища. Естественной восточной границей памятника является склон террасы.

В 2012 г. в юго-западной части памятника, где в обрезе берега наиболее четко читались выходы обожженной докрасна глиняной обмазки, был заложен раскоп площадью 64 м². Поверхность раскопа довольно круто падает с севера на юг (склон надпойменной террасы); на линии протяженностью 8 м падение склона составляет почти 1,20 м. Исследование данного участка поселения привело к вскрытию двух гончарно-обжигательных горнов (см. рис. 3).

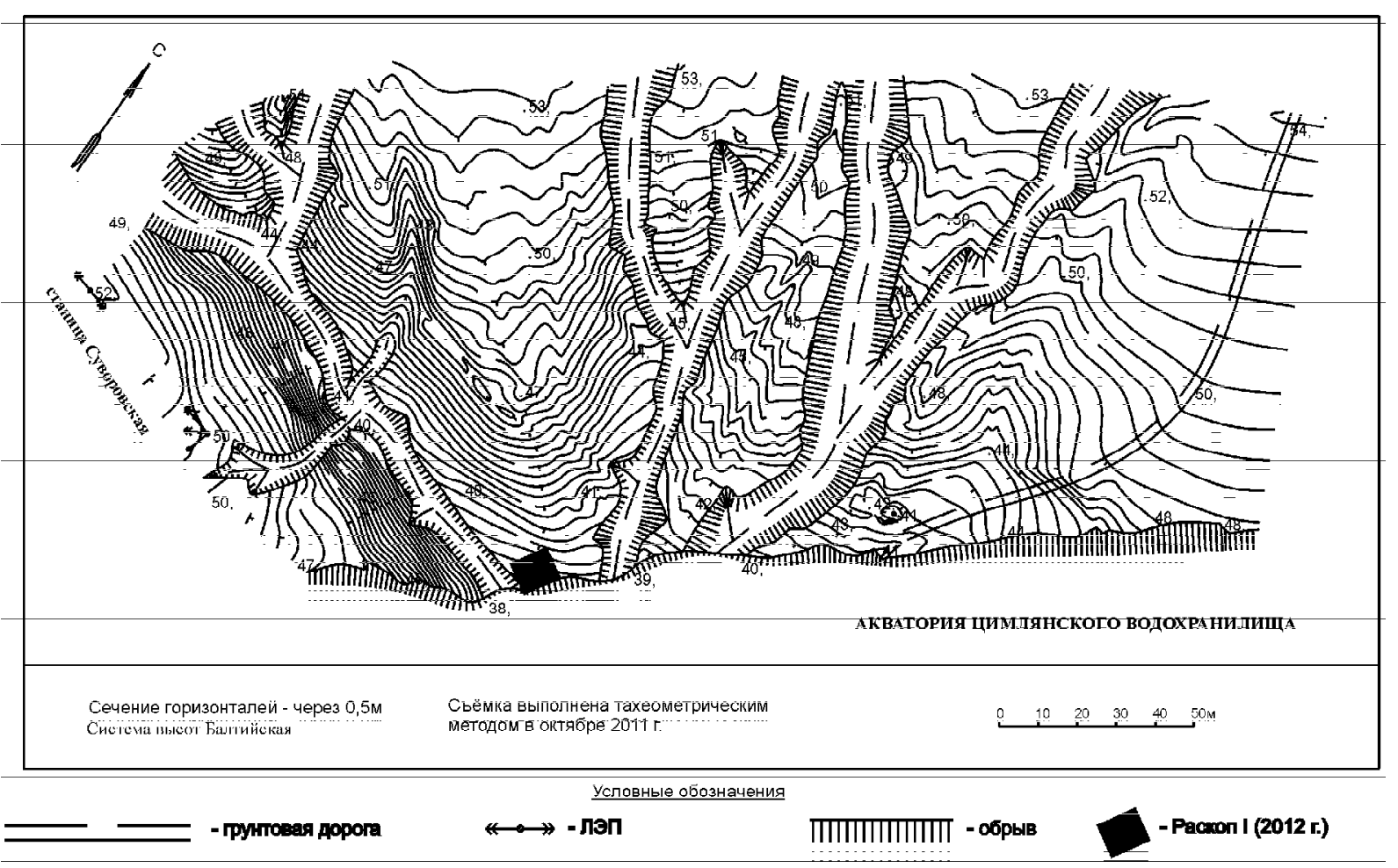

Рис. 2. Топографический план гончарно-ремесленного центра у станицы Суворовская 
Поселение Суворовское I - 2012

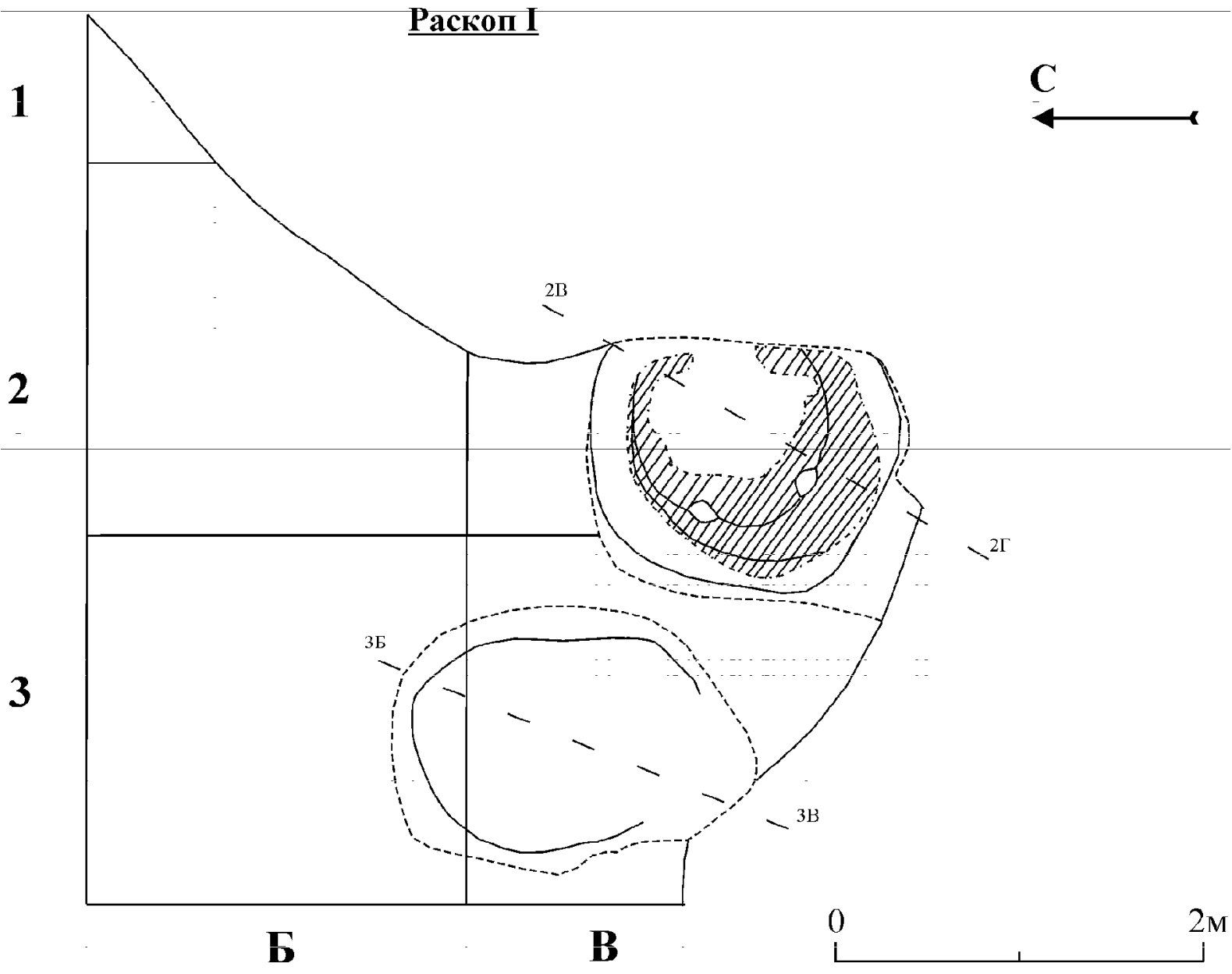

Условные обозначения

$\longrightarrow$ - гонтуры горизонта пода топки

---- - контуры гори'зонта свода топки

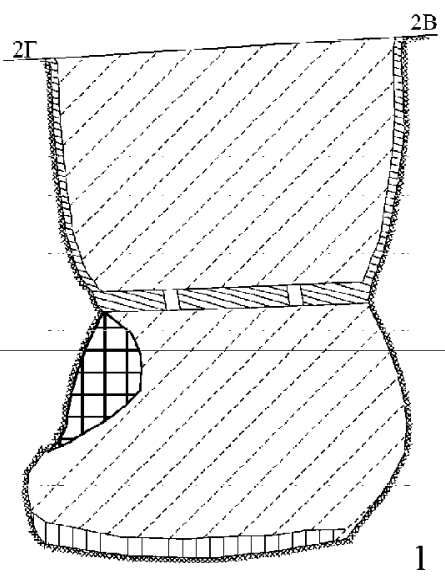

-.-.- контуры сохранившейся обжнгательной камеры

- обозначение стенок и дна обжигательной камеры

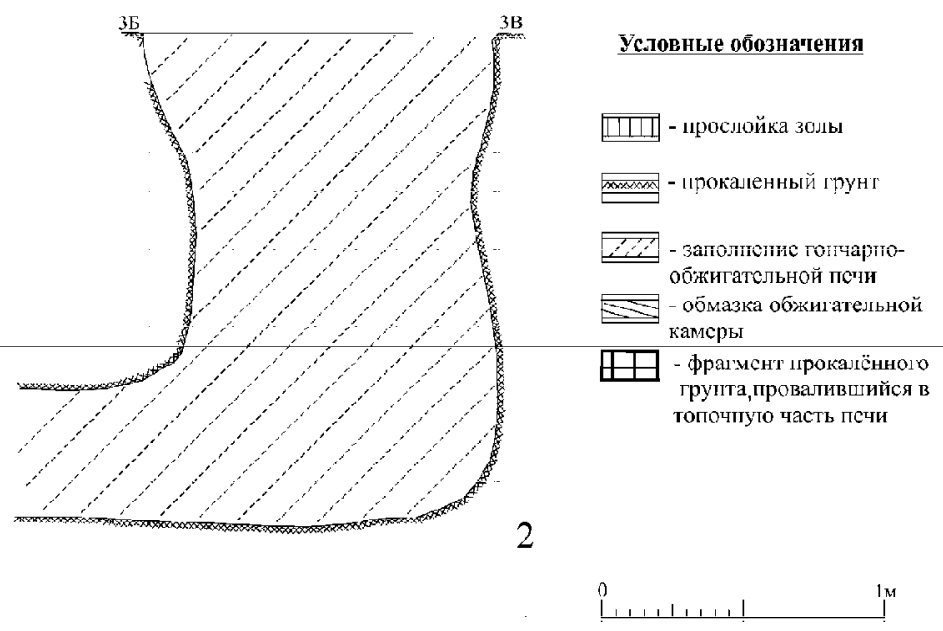

Рис. 3. Гончарно-обжигательные горны. План и профили:

1 - профиль горна № 1; 2 - профиль горна № 2 
Гончарно-обжигательный горн № 1 был вырыт в материковом суглинке и состоял из двух частей: топки, устье которой выходило в береговой обрез, и обжигательной камеры, расположенной над топкой. Юго-восточная часть горна оказалась разрушена в результате обрушения берега по причине весенних паводков.

Объект ориентирован по линии ЮЗ-СВ.

Топка в плане овальная, несколько вытянутая по направлению к устью. Размер пода топки по линии С-Ю - 1, 75 м, по линии 3-В - 1,4 м. Стенки топки почти отвесные, высота их от 0,4 м при устье до 0,7 м в средней части топки. Свод плоский с небольшим уклоном от задней стенки к устью. Устье топки выходило на берег. Оно представляет собой небольшое четырехугольное в плане отверстие размером $0,4 \times 0,4$ м. Над подом топки устье расположено примерно на высоте 0,3 м. Стенки и свод топки были обмазаны глиной. Обмазка хорошо обожжена, серо-оранжевого либо серо-зеленоватого цвета. Грунт вокруг топки прокален до ярко-красного цвета. Под топки покрыт 0,05 м прослойкой пепла, золы и имеет светлосерый, местами черный цвет.

Обжигательная камера размещена над сводом топки. В плане она округлая, диаметром примерно 1,10 м. Высота сохранившейся части камеры около 0,95 м. Пол камеры находится на своде топки и представляет с ней одно целое. Под и стены обжигательной камеры обмазаны глиной и обожжены. Толщина обмазки доходит до 2 см. Обмазка темносерого цвета. Под обмазкой просматривался ярко-оранжевый прокаленный грунт. Общая мощность перекрытия между топкой и обжигательной камерой достигает 0,4 м.

Обжигательная камера соединена с топкой посредством каналов, которые имеют цилиндрическую форму, диаметром 0,10 м. Так как дно обжигательной камеры было повреждено, удалось зафиксировать только два таких канала. Стенки каналов обмазаны глиной. В заполнении обжигательной камеры было найдено большое количество обмазки (обвалившийся свод), а также встречены фрагменты костей и керамики. В заполнении топки также встречены фрагменты керамики и кости животного.

Гончарно-обжигательный горн № 2 был обнаружен в южной части раскопа, западнее горна № 1. Данный объект был также вырыт в материковом суглинке и состоял из топки и обжигательной камеры. Обжигательная камера не сохранилась. По всей видимости, она просела в топку горна. Следовательно, удалось проследить только общие очертания стенок и пода. Объект ориентирован по линии ЮЗ-СВ. Топка в плане овальная, несколько вытянутая по направлению к устью. Грунт вокруг топки прокален до ярко-красного цвета. Размер пода топки по линии С-Ю невозможно проследить, по линии 3-В - 1,4 м. Несохранившееся устье топки, по всей видимости, выходило на берег. Однако стоит отметить, что горны № 1 и № 2 находились на одном уровне и, по всей видимости, имели общую предпечную рабочую площадку. Предположительно данная площадка была организованна на месте еще одного гончарно-обжигательного горна, который был разрушен раньше. Предполагаемые границы «третьего» горна с трудом прослеживались на уровне современной береговой полосы, и были перекрыты песчаными наносами.

Открытые гончарно-обжигательные горны аналогичны по конструкции и расположению на памятнике с гончарными комплексами открытыми в начале 50-х гг. ХХ в. (см. рис. 4). Интересен тот факт, что на месте рабочей площадки, которая являлась общей для горнов № 1, № 2, прослежены контуры гончарно-обжигательного объекта. Как было отмечено выше, слабые следы читались на современной береговой линии, которая перекрыта песчаными наносами. Такое месторасположение горнов, а также перестройка одного из них под рабочую площадку было также зафиксировано И.И. Ляпушкиным [6, с. 331].

Исследователем было выделено существования двух разновидностей горнов. Общей характерной для них чертой являлось наличие двух частей - топки и обжигательной камеры, которая находилась над топкой и была связана с ней посредством нескольких каналов. Основной отличительной особенностью горнов было наличие или отсутствие опорного столба, который находился в топке и поддерживал обжигательную камеру [1, с. $73 ; 5$, с. $103 ; 7$, с. 110 , рис. 17$]$.

Характерной чертой поселения у станицы Суворовской является высокая концентрация гончарно-обжигательных горнов на небольших по площади участках, что в свою 


\section{АРХЕОЛОГИЯ}

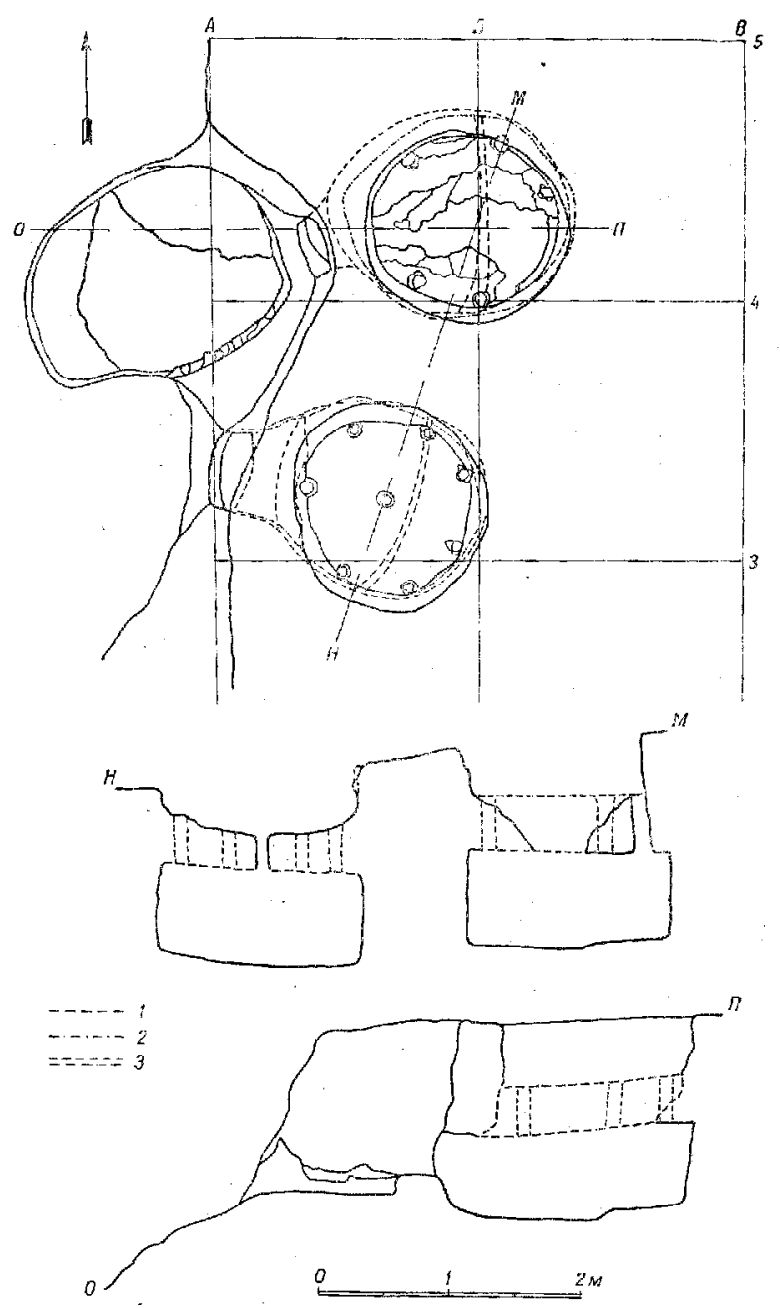

Рис. 4. План и профили полуземлянок, найденных И.И. Ляпушкиным на Суворовском поселении в 1951 г.

Примечание. Источник: [6].

очередь указывает на гончарно-ремесленный характер всего памятника.

В пользу данного предположения говорит и открытие рядом с печами скопления большого количества керамического материала. Стоит отметить, что керамика сильно фрагментирована, а наличие большого количества профилей разных типов сосудов, не всегда имеющих правильную форму (а в некоторых случаях прослежены явные следы брака), позволяет говорить о производственном процессе, в результате которого не всегда получался готовый продукт. Данное скопление керамики расширяется по мере разборки верхних слоев, что в свою очередь можно трактовать как некий сброс негодной керамической продукции.

Фрагменты керамики указывают нам на известные экземпляры салтово-маяцкой посуды (см. рис. 5). На памятнике присутствуют как кружально-столовая посуда (кувшины) (см. рис. 5, 1), так и кружально-кухонные сосуды с характерными прочерченными линиями на поверхности тулова сосуда (см. рис. 5, 2). Более детальный анализ керамического комплекса, на наш взгляд, заслуживает отдельной работы. В связи с этим отметим только некоторые особенности керамики, которые были отмечены по результатам работ. Во-первых, на памятнике были найдены фрагменты котлов с внутренними ушками, отсутствие которых раннее характеризовало памятник [6, с. 335] (см. рис. 5, 3). Во-вторых, среди керамики за все время изучения не встречено ни одного фрагмента амфор, которые характерны для салтово-маяцкой культуры, а также практически нет лепной керамики.

Стоит отметить еще один важный аспект, связанный с наличием мастерских, где гон- 

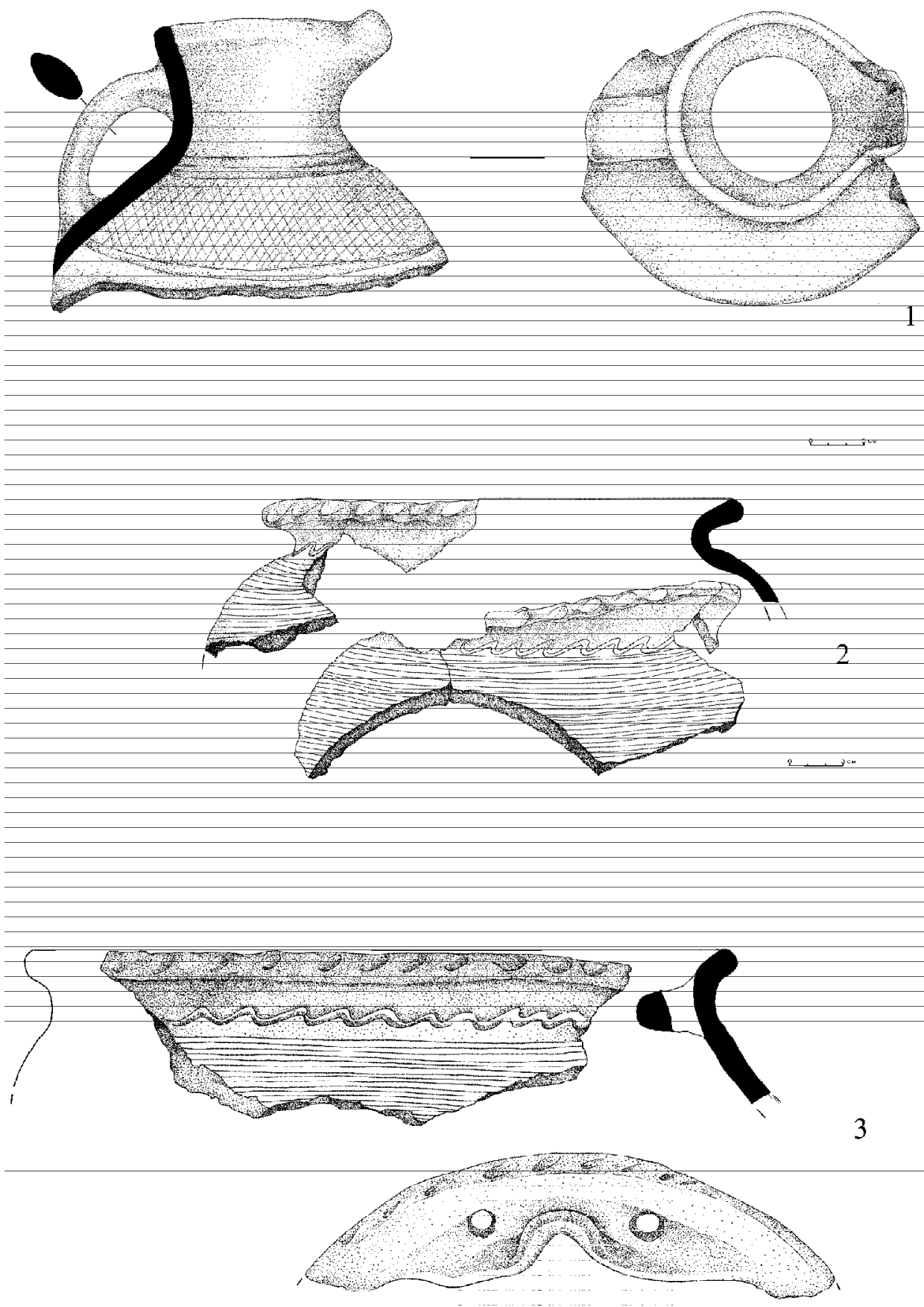

Рис. 5. Поселение Суворовское I:

1 - фрагмент столовой кружальной керамики; 2 - фрагмент кухонной кружальной керамики; 3 - фрагмент котла с внутренним ушком

чар изготовлял сосуды для дальнейшего обжига. Как уже отмечалось выше, И.И. Ляпушкин в ходе своих исследований помимо гончарно-обжигательных печей раскопал две полуземлянки (см. рис. 6). Из описания, приведенного исследователем, следует, что обе полуземлянки имели прямоугольную в плане форму и были вырыты в почвенном-материковом слое. Пол в полуземлянках глиняный, ровный, хорошо утрамбованный. В обоих случаях прослежено небольшое количество маленьких в диаметре ямок, которые были сооружены под столбовые конструкции. В полуземлянке № 1 в углу помещения обнаруже- 


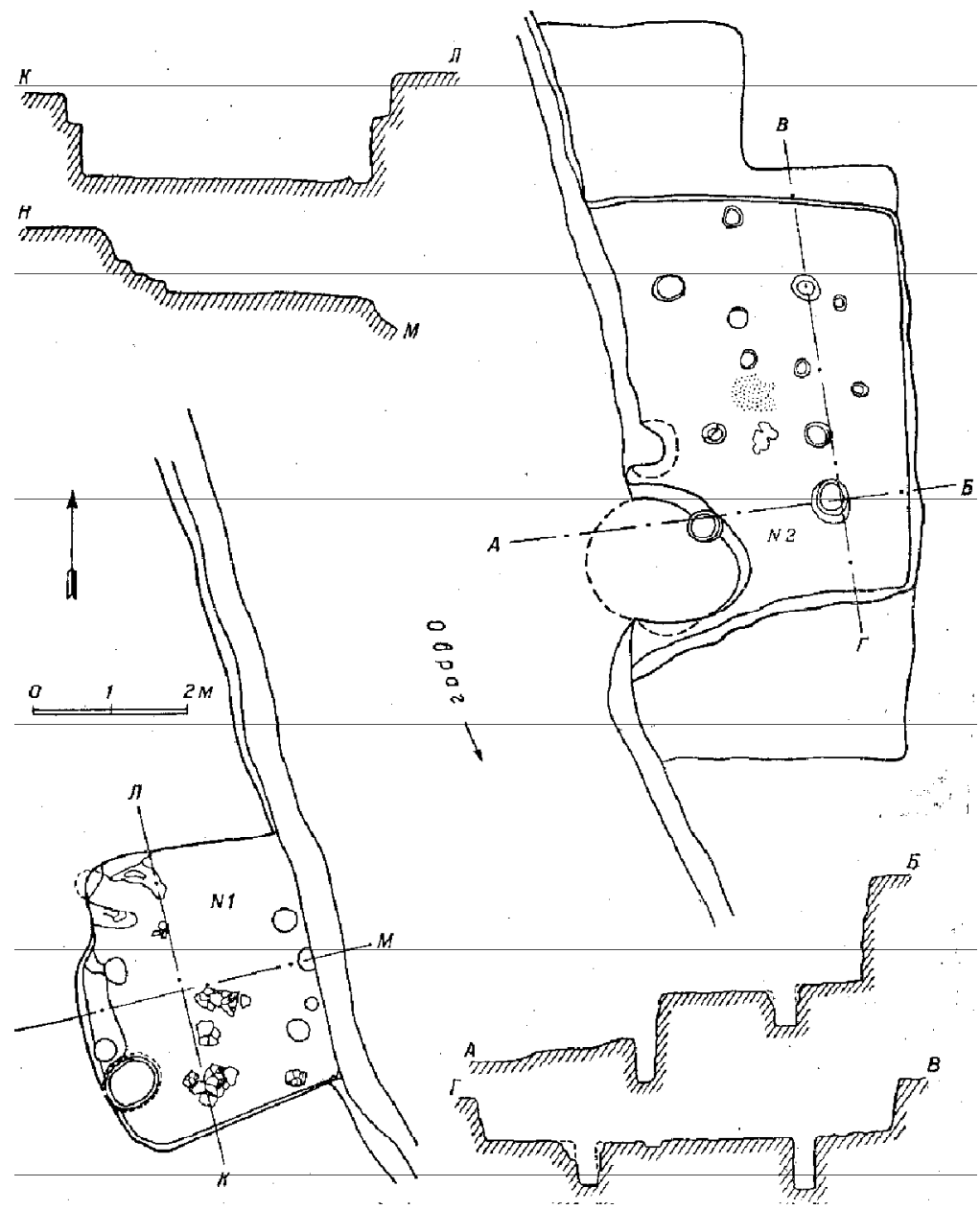

Рис. 6. План гончарно-обжигательных печей, найденных И.И. Ляпушкиным на Суворовском поселении в 1951 г.

Примечание. Источник: [6].

ны остатки развалившегося глинобитного очага овальной формы. В полуземлянке № 2 в центре помещения найдены следы открытого очага. Примечательно, что при раскопках обоих объектов было зафиксировано довольно большое количество костей животных и фрагментов глиняной посуды. Обе полуземлянки разрушены оврагом, что осложнило трактовку данных объектов [6, с. 326].

При изучении аналогичных гончарных центров салтово-маяцкой культуры были отмечены схожие объекты, которые трактовались как мастерские ремесленника (Маяцкое, Верхнеольшанское селище и т. д.) [10, с. 136-141]. При этом отмечалось наличие в специализированных гончарных районах построек, которые представляют собой прямоугольные в плане полуземляночные сооружения. Некоторые исследователи предполагают, что это могли быть специальные сушилки [8, с. 97-98; 11, с. 140].
Еще один схожий комплекс был вскрыт при изучении селища салтово-маяцкой культуры у с. Подгаевка, расположенном на берегу Деркула-левого притока Северского Донца [2, c. 267]. На данном памятнике также была исследована аналогичная полуземлянка, которая имела прямоугольную форму. Пол в ней - хорошо утрамбованный материк, сверху покрытый тонким слоем глины со следами обжига. В югозападном углу жилища была обнаружена хозяйственная яма. В дальнейшем полуземлянка была перестроена, хозяйственная яма была увеличена, а дно ее приспособлено под предпечную площадку для первой печи. Всего в данный комплекс входило пять гончарно-обжигательных печей. Три из них сооружены последовательно одна за другой, сменяя друг друга, а две были сооружены рядом так, что устья топок выходили на одну предпечную площадку, которая была сооружена на месте гончарно-об- 
жигательной печи № 3. То есть после того, как печь № 1 пришла в производственную негодность, ее разобрали до уровня предпечной площадки, оставшуюся часть камеры засыпали отходами от производства - фрагментами битой и бракованной керамики, золой, обломками стен печи, сверху перекрыли слоем песка и глины. Таким образом, на месте печи № 1 сделали предпечную площадку к печи № 2, которая повторила судьбу предшествующей конструкции и в итоге была преобразована в рабочую площадку для печи № 3. Данный гончарно-ремесленный комплекс датируется VIII-X вв. [2, c. 269]. В результате мы можем проследить сходство конструкций не только гончарноремесленных объектов, но и полуземлянок.

Таким образом, на памятнике Суворовское I прослежены структурные элементы гончарно-ремесленного производства, которые позволяют предположить, что перед нами специализированный гончарный район. Во-первых, это подтверждается большим количеством гончарно-обжигательных горнов, в ряде случаев имеющих общую рабочую площадку. При этом некоторые горны в дальнейшем были разрушены и преобразованы в предпечные площадки для новых объектов. Во-вторых, это места сбросов керамического материала, среди которого присутствуют бракованные фрагменты керамики, на которых явно видны следы производственного процесса. В-третьих, присутствуют хозяйственные постройки, которые с некоторой долей вероятности можно трактовать как мастерские ремесленника. Все это свидетельствует о длительности существования данного производственного центра.

Следовательно, закономерно возникает вопрос: на сколько правомерно выделять гончарно-ремесленный центр в особый поселенческий тип в структуре бытовых памятников салтово-маяцкой культуры? По мнению В.С. Флерова, специализированных поселений ремесленников, полностью оторванных от занятия сельским хозяйством, Хазария не знала, он также отмечал, что ремесло в то время не отделялось от сельского хозяйства и носило сезонный характер, особенно в климатической зоне лесостепи [11, с. 23]. Однако найденные гончарно-ремесленные объекты на памятнике Суворовская I характерны как для лесостепного локального варианта, так и для степной зоны распространения салтово-маяцкой культуры. Конечно, довольно сложно на данном этапе исследования определить, насколько удалены были эти центры от других поселенческих объектов. Возможно, в некоторых случаях гончарные мастерские являлись лишь частью более крупного археологического памятника (городища). Однако, анализируя топографию поселения Суворовское I, становится ясно, что данная местность не подходила для создания крупного поселка, где бы существовали другие виды деятельности.

При этом стоит обратить внимание на различные стадии развития гончарства, которые характерны для степного и лесостепного вариантов салтово-маяцкой археологической культуры. Как отмечала С.А. Плетнева, если в степи керамическое производство уже находилось в руках ремесленников, то в лесостепи оно еще оставалось на стадии домашнего промысла [9, с. 114]. Но на данный момент в лесостепи открыты гончарно-ремесленные комплексы с полным циклом производства на Верхнеольшанском и Маяцком селище [10, с. 178].

Выделение определенных типов стационарных памятников внутри салтово-маяцкой культуры, которые характерны для узкой специализированной направленности на изготовление высококачественных гончарных изделий, способствует дальнейшему изучению некоторых социально-экономических и этнокультурных процессов, которые протекали внутри Хазарского каганата.

\section{СПИСОК ЛИТЕРАТУРЫ}

1. Артамонов, М. И. Средневековые поселения на Нижнем Дону (по материалам Северо-Кавказской экспедиции) / М. И. Артамонов // Известия ГАИМК. - 1935. - ВЫп. 131. - 118 с.

2. Красильников, К. И. Гончарная мастерская салтово-маяцкой культуры / К. И. Красильников // СА. - 1976. - № 3. - С. 267-278.

3. Красильников, К. И. Идентифицирующие признаки населения степного Подонцовья в структуре Хазарского каганата / К. И. Красильников, Л. И. Красильникова // Хазары: миф и история : сб. ст. - М. ; Иерусалим, 2010. - С. 153-182.

4. Ляпушкин, И. И. Археологические памятники в зоне затопления Цимлянского водохранилища / И. И. Ляпушкин // Материалы и исследования, по археологии. - 1958. - № 62. - С. 227-262. 
5. Ляпушкин, И. И. Памятники салтово-маяцкой культуры в бассейне р. Дона / И. И. Ляпушкин // Материалы и исследования, по археологии. 1958. - № 62. - С. 85-150.

6. Ляпушкин, И. И. Средневековое поселение близ ст. Суворовской / И. И. Ляпушкин // Материалы и исследования по археологии. - 1958. - № 62.С. 323-336.

7. Миллер, А. А. Археологические работы Северо-Кавказской экспедиции Академии в 1926 и 1927 гг. / А. А. Миллер // Сообщения ГАИМК. 1929. - C. 60-122.

8. Плетнева, С. А. Гончарные мастерские Маяцкого комплекса / С. А. Плетнева, К. И. Красильников // Маяцкий археологический комплекс : сб. науч. тр. - М., 1990. - С. 92-121.

9. Плетнева, С. А. От кочевий к городам. Салтово-маяцкая культура / С. А. Плетнева // МИА. 1967. - № 142. - 198 c.

10. Сарапулкин, В. А. Керамика и керамическое производство лесостепного варианта салтово-маяцкой культуры : дис. ... канд. ист. наук / Сарапулкин Владимир Александрович. - Липецк, 2003. (Рукопись).

11. Флеров, В. С. «Города» и «замки» Хазарского каганата. Археологическая реальность / В. С. Флеров. - М. : Мосты культуры, 2011. - 264 с.

\section{REFERENCES}

1. Artamonov M.I. Srednevekovye poseleniya na Nizhnem Donu (po materialam Severo-Kavkazskoy ekspeditsii) [The Medieval Settlements on the Lower Don (Based on the Proceedings of the North Caucasus Expedition)]. Izvestiya GAIMK, 1935, no. 131, p. 118.

2. Krasilnikov K.I. Goncharnaya masterskaya saltovo-mayatskoy kultury [The Pottery of SaltovoMayaki Culture]. Sovetskaya Arkheologiya, 1976, no. 3, pp. 267-278.

3. Krasilnikov K.I., Krasilnikova L.I. Identifitsiruyushchie priznaki naseleniya stepnogo Podontsovya v strukture Khazarskogo kaganata
[The Identifying Population's Features of Steppe Podontsovye (Don Region) in the Structure of Khazar Khanate]. Khazary: mif $i$ istoriya: $s b$. st. [Khazars: Myth and History. Collected Articles]. Moscow, Ierusalim Publ., 2010, pp. 153-182.

4. Lyapushkin I.I. Arkheologicheskie pamyatniki v zone zatopleniya Tsimlyanskogo vodokhranilishcha [Archeological Sites in the Flood Area of Tsimlyansk Reservoir]. Materialy i issledovaniya po arkheologii, 1958, no. 62, pp. 227-262.

5. Lyapushkin I.I. Pamyatniki saltovo-mayatskoy kultury v basseyne r. Dona [The Sites of SaltovoMayaki Culture in the Basin of the Don River]. Materialy $i$ issledovaniya po arkheologii, 1958, no. 62 , pp. 85-150.

6. Lyapushkin I.I. Srednevekovoe poselenie bliz st. Suvorovskoy [The Medieval Settlement Near Suvorosvkaya Site]. Materialy $i$ issledovaniya po arkheologii, 1958, no. 62, pp. 323-336.

7. Miller A.A. Arkheologicheskie raboty SeveroKavkazskoy ekspeditsii Akademii v 1926 i 1927 gg. [Archaeological Excavations of the North Caucasus in 1926-1927]. Soobshcheniya GAIMK, 1929, pp. 60-122.

8. Pletneva S.A. Goncharnye masterskie Mayatskogo kompleksa [The Potteries of Mayaki Complex]. Mayatskiy arkheologicheskiy kompleks: sb. nauch. tr. [Mayaki Archaeological Complex: Collected Scientific Articles]. Moscow, 1990, pp. 92-121.

9. Pletneva S.A. Ot kocheviy k gorodam. Saltovomayatskaya kultura [From Nomads to the Cities. SaltovoMayaki Culture]. MIA, 1967, no. 142, 198 p.

10. Sarapulkin V.A. Keramika i keramicheskoe proizvodstvo lesostepnogo varianta saltovomayatskoy kultury: dis. ... kand. ist. nauk [Pottery and Ceramic Production of the Forest-Steppe Type of Saltovo-Mayaki Culture. Cand. hist. sci. diss.]. Lipetsk, 2003. 285 p. (Manuscript).

11. Flerov V.S. "Goroda” $i$ "zamki" Khazarskogo kaganata. Arkheologicheskaya realnost ["The Cities" and "The Castles" of Khazar Khanate. Archaeological Reality]. Moscow, Mosty kultury Publ., 2011. 264 p.

\section{Information About the Author}

Yakov A. Kiyashko, Postgraduate Student, Department of Archaeology, World History and Tourism, Volgograd State University, Prosp. Universitetsky, 100, 400062 Volgograd, Russian Federation, kiyashko.ya@gmail.co, adsi@volsu.ru.

\section{Информация об авторе}

Яков Алексеевич Кияшко, аспирант кафедры археологии, зарубежной истории и туризма, Волгоградский государственный университет, просп. Университетский, 100, 400062 г. Волгоград, Российская Федерация, kiyashko.ya@gmail.com, adsi@volsu.ru. 